UDC 316.6: 69.059.25

Ana BAZAC

\title{
REPAIR: A DISLOCATING CONCEPT AND ITS VICISSITUDES
}

\begin{abstract}
The concept of repair - and its very interesting synonyms (but, as we know, the synonyms are never perfectly superposing) - emphasises both its socially constructed meanings and its extratheoretical relations or practical functions. My paper has two methodological goals. The first corresponds to the focus on the historical and social roots of the place of repair activities in different human societies, while the second consists in the insistence on the causes and consequences of the repudiation of repair in the present era of world capitalism.

Passing over the etymological sources of the specific action of repair, we cannot neglect its interdependence with both the labour processes and the scarcity that characterised ab initio the human societies. The paper explains how rarity and social domination relations are ontological factors directly determining the activities of repair, and also how the indirect ontological factors of toolmaking ability and the level of the means of production (or, more generally, of productive forces) and the structural relations intertwine and fuel these activities. The entire logic of epistemological origins but also of the historical attitudes towards repair reflects the role of the social domination, concretely, of the capitalist relations imposing only a fragmented, anti-ecological perspective on nature-society.
\end{abstract}

Keywords: repair, technology, compensation, maintenance, consumption, capitalism.

\section{Warning}

The unpopularity of the concept of repair in the present society is due to the capitalist logic of economy: the more the new goods are bought, the higher are the profits, and thus, the markets being assured, the more is the possibility to continue and develop within this logic the process of production and the productive forces. The logic of the capitalist economy has in view and follows only the private profit logic, and thus any action of repairing seems to it inimical and subversive.

However - and letting aside that even the productive process of new goods involves in a way or another actions of re-adjustment, repairing of parts of machines and devices, and re-structuring of the goals and process as a whole because of the previous spoiling, breaking, impairing of mechanisms and instruments, and thus letting aside the economic function of repair even in capitalism - the repair had and has a strong social function: that to compensate the weak access of ordinary people to new goods and new means of production, and that to compensate the status of poverty and lack of livelihood.

But as we know, compensation is a con- 
cept with a strong psychological aspect. The action to repairing something is, obviously, determined by the need for that object but, at the same time, by the need to have its technical functions realized: as if that object would be new. For this reason, to compensate means to make once more, even anew, a certain object, as if this action of doing again would take part from the original action. The human being who carries on renovation, reparation, redressing, fixing up, has a complex of double feelings: on the one hand, it obviously know that its actions of repairing are supplementary/adding to the "normal" actions, at least to the ideal/imagined/planned ones; and the actions of repairing may be boring or even tiresome, so they may be not welcome; in front of them, the feeling is rather pessimistic; on the other hand, it knows that, since the repair is absolutely necessary, it must be done at one's best, and after finishing this work the repaired piece will seem as a new one; thus, in front of this supplementary activity, the human must encourage itself and is rather optimistic: the repaired piece is like a new one, then it was worth the effort.

\section{Etymology}

And etymology shows this complex of feelings and ideas. A philosophical premise of the concept of repair may be found ab initio. Letting apart a possible speculation concerning the link between the Greek exclamation $(\rho \varepsilon)$ expressing surprise or astonishment or calling to attention and, on the other hand, the Latin prefix re, this prefix itself signifies the permanent renewing of an action since it has revealed to being limited, unfinished and requiring an improvement. Thus the response to an action is a re-action, i.e. a) the continuity of the action, b) a new action somehow in contrary, even in the opposite sense to the first, c) the return to the state anterior to the action. If the conscience of the now inadequate character of an entire set of actions is acute, the reactions constitute a re-form. Reform means first of all just this conscience that things are already obsolete and have to be brought out to reforming them. Secondly, reform shows the intention to change, thus the change as such, irrespective of the directions of this action: backward, (and from this standpoint there is an overlap between reform and the etymological sense of revolutio) or forward. But thirdly, reform points out the effort to improve the old state, to recover from certain languidness through some concrete measures, to correct the ill aspects without exiting from the considered framework, on the contrary giving to it the genuine form, restoring it.

An action of repairing is a re-form. A special one, since rĕpăro, -āre meant to prepare again, to recommence, to resume, to recover, to recuperate, to reconstitute, to substitute, to restore, to encourage, to rebuild the soul: a new form or the form approached again as if the recommencement would mean to forget/bracket the old form, and the construction of the new one to be the first action. Therefore, repairing was, consciously, both material reforming and psychical encouragement that one must never retreat and yield.

The root of the Latin verb is păro, -āre that means both to prepare oneself, to have the intention, to gain, to buy, to make, to arrange, to establish, and to consider as equal, to give the same importance, to compare, to share, to make a deal. In other words, to resume an action means to be aware of the history of that 
action: that there were the first psychical and material preparations in order to achieve something, and that in these preparations as well as in the action as such one does judge, measure, search the best way between equally possible paths, and the golden mean and harmony from the level of which one considers the things and the results of actions.

\section{The Ontological Basis}

The living being - and man, especially is based on repair, since it is connected to the milieu, reacts and adapts. And the actions of repairing lead to the augmentation of the functionality of living parts (see Opris, 2013).

Likewise, man is, obviously, a homo reparans, a species producing artificiality and fixing it (Spelman, 2002). However, this assumption must be enriched / concretized in the social reality.

Since rarity was an ontological factor of the human being (Sartre, 1960; but also Bazac, 2007, 2008), the efforts for constructing the material milieu of humans took place in the framework given by this factor and, accordingly, of the social differentiations, division and oppositions. And though the level of civilisation - of diffusion of unique cultural innovations/creations - thus of the artificial/cultu$\mathrm{ral} /$ human was low, and there were not so many necessary artificial objects for the human life, people have constructed and treated them in an economical manner: they used every part of the material things they had at their disposal, and certainly, this meant to re-use them, to re-form them, to mend, to patch up and even mess up, to refit and renovate them, thus to improvise/to make afresh the same object or a new one but with the same function without preparations/initial planning but, at the same time, to challenge and develop the creative imagination in order to handle with the existing material data.

Consequently, the repairing attitude towards things must be related to the preventive attitude towards nature.

Indeed, we must not idealize the ecological, preventive and anticipative behaviour of the ancient people (Krech III, 2000; Harkin \& Lewis, 2007). The principle of repair, implied in the general attitude towards the material artificial environment of humans, was the inevitable result of the scarcity of means of production (both means of work and objects of work). However, if it's no wonder that in front of shortages, the ancient people behave in a wild manner, though there were many ideas denoting an ecological consciousness (Chew, 2001). But would the present dominant behaviour towards nature be a simple continuation of the ancient one?

Going further, obviously, the principle of repair directed, first and foremost, the activity of the labour force, from the maintenance and repairing of the tools and their constitutive or auxiliary parts to the intellectual activity of copying (see the palimpsest custom).

Therefore, when the cause does disappear the effect disappears too, does it? The unpopularity of the principle of repair would be the consequence of the dilution of scarcity? And, since this dilution seems to us as absolutely positive, would its result be positive too? Well, in society there is never only one cause of a phenomenon, and thus neither the phenomenon nor a certain cause of it may be reduced to one aspect and a single inference.

The rise of the modern social wealth was, certainly, the result of the development of 
modern productive forces, but also of the colonial type gathering of goods. Only the intertwining of these two causes explains the modern social wealth: the Roman Empire has amassed huge wealth, but in the absence of the modern mechanical technology that substituted the tools with machines, neither the wealth was sustainable and nor has it succeeded to compensate the destructive forces attacking the Empire. When speaking about destructive forces, I do think not even to the migratory peoples or to those who fought against the Roman conquerors: I speak about internal structural characteristics as the "economic stratification" (Motesharrei, Rivas, \& Kalnay, 2014) that may generate even alone the collapse / the inequality in the sharing of resources, and the "carrying capacity" of a more and more complex bureaucratic organisation in the frame of this kind of society. (The concept of carrying capacity was coined by Catton, 1976). More: the lack of modern means of production has manifested through the exclusively extensive agriculture and thus through both the quantitative rise of the structures of domination (army) used to acquire new lands and resources, and the subordination of the logic of management to this requirement of new territories, clearer, to the logic of the dominant elites of this type of society.

While: only the betterment of the modern productive forces through the science-technology revolution, and the agglomeration of goods without the betterment/change of the structural relations of the present system have no the strength to stop the destructive tendencies manifested in the prolonged and ubiquitous crisis of the present society. The old scarcity seems to be surpassed as a result of the extraordinary development of the productive forc- es, they involve and lead to an intensive manner of use of resources ${ }^{1}$, but the structural relations of the present system generate wars as if the only logic of economy would be extensive, and inequality and famine (World Hunger Again on the Rise..., 2017), and polarised repartition of high-quality protein and food, as if the present productive forces would not exist and the world would stay under the aegis of the old scarcity. In other words, though the transition from the extensive economy (always new lands, more labour force etc.) generated by weak productive forces to the intensive one (total use of raw materials) is possible just on the ground of the scientific-technological revolution - and thus, the economical use of labour force, i.e. the fuelling of its creative ability, is possible too - the capitalist structural relations not only use the development of the productive forces in a contradictory manner, both impelling and opposing this development, but also behave in an obsolete way, as if the productive forces still would be weak and requiring the acquisition of new means of production by plundering them.

From an ontological point of view, rarity as such is not the only factor explaining the material (and spiritual) state of poverty of the humans and of the world (Gorz, 1962) ${ }^{2}$, and

1 This intensive manner - that consists in the active circular process when all the secondary materials are used again - coexists with the extensive one that means the extensive use of raw materials swindled from old and new "vital spaces" for the imperialist capital (see Custers, 2017).

2 Long ago, André Gorz, 1962, has pointed that: 1) the "normal" poverty does not suppose simply the lack of the livelihood, but the lack that forbids to living as a human being in the 
accordingly, neither the recourse to repair activities in order to survive or make both ends meet. An ontological factor generated by rarity but having the same ontological place is the social domination: both leading to practices of compensation, through which the repair was a main one.

Therefore, the dissolving of rarity does not lead to the disappearance of the activities of repair when the other ontological factor, the social domination, lasts.

But things are more complicated: the tool-making ability (Franklin) of humans is another ontological factor, and its result, the level of the means of production - another one. Now, the logic of the above ability involves the development of these means all the way. "When something can be done, it will be". Irrespective if these means are war or peace means, or allowing an extensive or an intensive economy,

given society; 2) at the level of the modern civilisation, man is "determined by the normative possibilities proposed to the entire population by the surrounding civilisation: possibilities as the model of man, or at least its future model". 3 ) If the individual has no the means to realise them, its humanity is excluded and diminishes. The excluded individual cannot even to choose (between the unattainable goods and those attainable), because one may refuse only what one has.4) "What is important is that, because the model is not considered as a luxury but as the rule, today, compared on the dominant model, there are more poor people than ever". Hence, 5) "there is not poverty when everybody 'is poor'...there is a general austerity, namely, unmet needs and whose satisfaction is postponed, but not under-humankind, a class deprived of human entitlements according to the norms of the surrounding civilisation". or irrespective of their scopes and consequences, they will be developed infinitely.

However, is this really the situation? Do people not think at all to the stakes of their deeds? Is there no difference between the intellectual curiosity to understand (to know how, not only to know why) and the practical endeavour all the way?

Certainly, there is, and the productive situation does not reflect only the productive ability of humans. The limits of the technological and productive deeds are not given directly by rarity and the social domination, but by the concrete social structural relations of a system, framing a certain society and mediating the mentioned ontological factors. The capitalist structural relations require and generate the use of the productive ability and scientific and technological cleverness according to the private interest to maximise the private profit: and this, irrespective of the costs and consequences of this use. Simply, the logic of the private interest externalises the costs and either does not care about the consequences or counter them with some partial, limited and local measures which, however, have no world, unitary/integrated scale and, thus, results. This is the basis of the proposition of a radical alternative to capitalism: this alternative is not an ideological fantasy, but the only solution for repairing the present state of nature and the world resources.

For this reason, it's absurd that the literature which correctly shows that the most serious scientific analyses emphasise that the continuation of the present logic of the growth economy is suicidal for the Earth and the human species as such and that just the earth/life /ecology sciences substantiate the necessity of a radical alternative to capitalism (Klein, 2013), 
arrives to the idea that the inducement to a new ecological culture, the protest movements and the local struggles against the growth economy would be tantamount to the clear proposition of the radical alternative to capitalism (Klein, 2015). These manners to substitute this proposition with critique and hopes, or even with a "right to withdraw" from the present (neoliberal) society of the citizens who refuse it (Dufour, 2009), are perverse, because: 1) there is no longer time from the standpoint of the nature-society relationships, and 2) there is no longer time from the point of view of the human beings which waste their unique life. Therefore, to consider the present (neo-liberal) appearance of capitalism as the only guilty for the "excesses" of poverty, exclusion, inequality - as if neo-liberalism would be a historical accident and would be counteract by a new "capitalism with a human face" - means to not understand the capitalist logic of economy that necessarily led to its present form.

And since nowadays the productive forces are able to solve not only the problem of scarcity but also of their own conditions and consequences, it results that neither rarity nor the level of productive forces are the cause of the present persistence of social domination. On the contrary, the capitalist structural relations (exploitation, capitalist competition and Core-Periphery international relations) and their supplementary political forms of violence constitute the hindrance to the alternative productive process that does no longer externalise the environmental and human costs.

Finally here, in the present situation of technology and its high productivity, the logic of private interest requires different measures to thwart this productivity and the reduction of profit rate: those to force the moral obsolescence of goods and that to oppose to the actions of repairing. The last measure is based on the declining prices of the industrial products as a result of the technological revolution. But if so, the logic of the capitalist production generating an inutile waste of resources and human energy once more appears irrational. And the contempt and obstruction of the repairing actions are the manifestation of this irrationality.

However and with the entire obstruction, at least the last decades have witnessed the development of counter-tendencies originating from the under-middle classes, but transformed into respectable strategies of approaching the materiality of things: repairing, maintenance, saving of energy and raw and processed materials.

In this frame, the functions of the actions of repair have in view to compensate both the poverty of the non-privileged social strata - as if there would have not been any difference between the old times marked by original rarity and the present ones when abundance becomes to be the ontological factor - and the high productivity of labour ${ }^{3}$ that has led to the decreasing of the profit rate. This decreasing means, in the average, stationary real wages/ they do not rise according to the rise of productivity, and thus the decrease of purchasing power. This is the origin of the present fever of repairing and reconditioning (and vintage and retro objects), as well as community type organisations aiming at maintaining and saving the existing artificial surrounding.

3 We remember that the high productivity of labor involves high level of technology. 
The Epistemological Basis

We should not ignore that the repair has an epistemological origin too. It is, within the cultural/cognitive ability, the trial and error pattern of thinking, the permanent correcting of our ideas, including those related to objects: which have to be maintained, cleaned, repaired, adjusted, according to the better understanding and to the anticipation of the ideal or, at least, good functioning of the material structures.

\section{Repair and Maintenance}

Though the two activities are similar (this is the standpoint of two Maintainers conferences, 2016 and 2017, see http://themaintainers.org/), as fixing-up for having the objects as "ready" and "ready-to-hand" (Graham \& Thrift, 2007, the last attribute being borrowed from Heidegger), we may relate them to different types of objects. While to say that the repair of the means of production sounds well, to say "the maintenance of clothing" is odd. On the contrary, maintenance is even a branch of engineering (Dhillon, 2006), therefore linked to the means of production. In this situation, the repairing as such seems to apply rather to consumer objects.

The present neo-liberal stage of capitalism reveals that there are differences between the maintenance in the private units and the maintenance in the public ones. While the former reflects and reproduces the concrete interests of the owners related to the ever growing world economic competition (and from this standpoint, sometimes is cheaper to maintain the old apparatuses etc., but sometimes is more expensive), the latter is rather simplified, postponed and occurs rather after crash situations: because in the public units there are public goods, not interesting for the private profit (or interesting only as the private capital can gain following the shortages resulted from the crisis of public units). This is the reason that the rhythm of repairing the infrastructure of public goods is dallying (Azul, 2017).

Repair and the Preference to the Naturalness of Consumer Objects

The above-mentioned economic and social cause generates also the more and more leaning toward natural means of health care: namely, not only because nowadays people are more circumspect towards the synthetic medicines, but also because these ones are more expensive than the natural teas and powders (Bazac, 2012).

However, even if the nostalgia for "the good old natural objects" is general and perhaps without any class differentiation, the availability of these goods has a strong class origin: not everyone can afford organic food, can one? The same class origin, i.e. in the interests of clothing producers dictating the fashion, can be seen in the present persistence of use of animal skin for clothing and furnishing, as if nobody would have heard about ecology and as if there would not be artificial substitutes of animal skin and furring: the natural skin and fur is expensive, showing a clear well-off class status, but at the same time, the fashion requires them and this leads even to a classless use; and since the animal skin is necessary for foot gear, the excess towards necessity appears clear-cut.

The "natural" preferences are related to an entire new practice of consumption: "radical" or "ethical", focusing on fair trade, consumer protests, green consumption, brand backlashes, 
green goods, boycotts and downshifting (Littler, 2008), but having no the power to change the logic of capitalist production. Instead, the new preferences are immediately included in the market economy.

\section{The Disregard towards Repair}

The explicit capitalist logic of "profit rush" has transformed the habits of the population - but this means also the change of sentiments of constancy, continuity and safety after the 1989 transition of the former socialist countries. In Romania, all the ruling "elites" have contributed to destroy the vocational education as well as the repair centers. Nobody does repair the footwear, the bed sheets or the furniture, though most people need it, because they are too poor to buy new objects of this sort.

We must not neglect that there is a difference between the repairing of the means of production - sometimes this repairing being un-necessary, because either the repair is too expensive or the substitution with new machines etc. is already sine qua non in order to arrive to a competing productivity - and the repairing of the consumer objects. Generally, this repair is not more expensive than the price of new objects, and people need it, including for sentimental reasons. Or, this means that the missing possibilities of repairing in countries like Romania counter just the principle of the (profitable) supply and (solvable) demand: because there are both the need and the solvable demand, and nevertheless there is no supply of repair centers.

The private profit generates also undemanded objects and practices related to the industrial agriculture: instead of repairing the damaged land and animals caused by this agribusiness, the present system continues to harm both nature and the consumers, and the big agribusiness corporations are so powerful that they impose even to cooperatives this harmful practice (Herman, 2017).

\section{Repair and the Ecological Goals}

The importance of repairing increased beyond the limits of the direct economic condition of people. It depends on the ecological conscience, more and more refined in proportion as the world ecological crisis aggravates. This conscience means the understanding not simply of the finitude of resources, but also of the "myth of resource efficiency improvements (the Jevons paradox, see Polimeni, Mayumi, Gianpietro, \& Alcott, 2008). Accordingly, and since a consumption frontier follows, without meaning a return to a primitive frugality/ascetic life, a reasonable analysis of the present expanded, useless and wasteful needs caused by the capitalist market logic, and the development of the valuing of many existing goods (including through repairing them) are necessary. From this standpoint, the concrete search of "postcapitalism" in Latin America (where repairing takes part of the "ecologies of knowledge", de Sousa Santos, 2011) is only an introduction.

Since the unmeasured expansion of wasteful goods for profit is the result of private property logic, it means that the ecological goals all the way (and not instrumentalized as private profit opportunities) have a class character too, irrespective of their apparently classless belonging. Hence, their solution is a radical transformation of the structural relations in order to support an economi- 
cal production subordinated to the real needs of the humans, and not to the private profit. In this respect, the pious praises of the frugal life and the calls for de-growth without expressly attack the causes of the unequal and disharmonious use, prevalence and depletion of resources and natural basis of the human life, are only waste of time of this human life: waste of the necessary time to search for ways to the alternatives towards the present dominant system. As the praise of frugality imposed to the majority of the population of the world is at least shameless, as the gradual de-growth keeping the capitalist logic is absurd. While: the theory that a capitalist ecological growth would solve the contradictions of the coupling nature-society and moreover all the geopolitical parts will win is only a wishful thinking. There is, certainly, an objective natural "carrying capacity" (Catton) of the humans of the Earth, but nowadays the biggest impediment to take it into account and prevent its exceeding is just the value choice guiding the real solving or its postponement ${ }^{4}$.

4 The capitalist frame of thinking permanently generates the habit to be afraid of the cost in the short term of the radical solving, and to consider the present problems in a way of nonecological literacy or "according to a [preecological] worldview" (Catton, 2008). Therefore, the above habit is constructed by the capitalist paradigm and consists of: 1) separation of fields/domains and objectives, 2) externalization of costs (within fragments/domains/firms) into the biggest/comprising system (nature, society), 3 ) separation of the parts from the whole (opposite to Aristotle), 4) consideration of parts as representing the whole/its tendency/its representative aspect.
Conclusions

The principle of repair, taking part from the general conception of economization of resources and human energy in order to freeing its creativity, is revolutionary: it imposes the restructuring of the logic of present economic activities according to their combined telos. This last concept sends us to the understanding of the reason to be of things (Bazac, 2017). And since the reason to be of the functioning of economy is its material and organizational structuring in order to assure the well-being of humans and, at the same time, the harmony of nature and society - i.e. the ecological harmony and preservation, and the economization of resources and human energy in order to freeing its creativity - it results that one can no longer accept the private lens /private interests in economy: because the adjusting of all the human interests and nature relationships is systemic, and requires an integrated, unitary view.

The revolutionary character of the concept of repair consists not at all in its implied suggestion that the solution to/against the poverty and inequality pushing people to live in a precarious way (and thus, to repairing instead of to buying new objects) would be the more egalitarian repartition of these objects, but on the contrary: that the solution is the transformation of the structural relations so as to forging a new position to the labor force, a position allowing both its control over production and society, namely, its anticipative control leading to a rational tackling of the upstream (the human needs, the resources, nature) and downstream (the direct and indirect results) of economy. 
In the same respect, one has to move away from the classic neo-liberal ideology celebrating the rapid substitution of objects, their "transience" (Toffler, 1970) ${ }^{5}$, irrespective of the irreversible waste of matter and energy (including human energy, as I said) necessary for this insobriety of the private capital. We have to understand (what Catton, 2008, p. 474 warned) that already any "cosmeticism" according to which some local and partial improvements would counterpoise the systemic multi imbalances and crisis is only a factor of deepening this crisis.

Obviously, a concept - here, the repair has a limited power to transform the ideas of the humans. It does it only in a complex of reasoning and arguments which are cogent according to their logic and correspondence with the real facts. But the concept discussed in this paper - the repair - has just the function of a premise of transformation of the ideas about the present world.

We have to trait in a responsible manner the epistemological complexity of the human knowledge: we conceive of very complex objects (so, we treat things in a separated manner) but at the same time we cannot relate them and understand the consequences, on short, medium and long term, of these objects and the separated theories. And at the same time, we must not forget that this lack of the human's understanding is historically and socially constructed.

5 Toffler's viewpoint was not only the song of the private owners in quest of profit sources, but it reflected also the state of the world in those times (before 1973), i.e. the imperialist Centre-Periphery domination that consisted in the low prices of energy and raw materials coming abundantly to the "first world".
Finally, though the concept of repair seems to illustrate the artificial part of the world - production, civilization - it sheds light on the dialectics of nature: its both regenerative and limited/finite capacity of existence, and, on Earth, its interdependence with the human society.

\section{REFERENCES}

Azul, R. (2017, October 24). Puerto Rico Power Blackout the Biggest in US History. Retrieved November 2, 2017, from World Socialist Web Site: http://www.wsws.org/en/articles/201 7/10/24/puer-o24.html.

Bazac, A. (2007). În jurul problemei cauzelor structurante: ontologia gramsciană a forţelor de producţie şi teoria rarităţii la Sartre. În Gramsci şi Sartre. Mari gânditori ai secolului $X X$ (pp. 97-113). Bucureşti: Editura Institutului de ştiinţe politice şi relaţii internaţionale.

Bazac, A. (2008) Sartre şi aventura conceptului de raritate. În A. Neacşu (Ed.), Sartre în gândirea contemporană (pp. 105-162). Craiova: Editura Universitaria.

Bazac, A. (2012). Significances of an 'Alternative' Health Care: the Health Column in a Romanian Post-Communist Popular Magazine. Debatte: Journal of Contemporary Central and Eastern Europe, 20(2-3), 151-169.

Bazac, A. (2017). Three Concepts in the History of the Knowledge of the World (Cause, Consequence, Telos) and a Conclusion. Biocosmology - NeOAristotelism, 7(2), 155-177. 
Catton, W. (2008). A Retrospective View of My Development as an Environmental Sociologist. Organization Environment, 21(4), 471-477.

Catton, W. R. Jr. (1976, April). Can Irrupting Man Remain Human? BioScience, 26, 262-267.

Catton, W. R. Jr. The World's Most Polymorphic Species: Carrying capacity transgressed two ways. Retrieved November 2, 2017, from http://www. jayhanson.org/page81.htm.

Chew, S. C. (2001). World Ecological Degradation: Accumulation, Urbanization, and Deforestation, 3000BC-AD2000. Walnut Creek, California: AltaMira Press.

Custers, R. (2017, September 18). L'Allemagne se sert en Mongolie. Retrieved November 5, 2017, from: http://www. investigaction.net/fr/lallemagne-se-serten-mongolie/.

de Sousa Santos, B. (2011, janvier-juin). Épistémologies du Sud. Études rurales, 187, 21-50.

Dhillon, B. S. (2006). Maintainability, Maintenance, and Reliability for Engineers. Boca Raton (Fl.): CRC Press Inc.

Dufour, D.-R. (2009). Le Divin Marché. Paris: Denoël.

Gorz, A. (1962, September-October). Avantpropos. Les Temps Modernes, 196197, 386-400.

Graham, S., \& Thrift, N. (2007). Out of Order: Understanding Repair and Maintenance. Theory, Culture \& Society, 24(3), 1-25.

Harkin, M. E., \& Lewis D. R. (Eds.) (2007). Native Americans and the Environ- ment: Perspectives on the Ecological Indian. University of Nebraska Press.

Herman, P. (2017, Septembre). Pratiques criminelles dans l'agroalimentaire. Le Monde Diplomatique. Retrieved November 5, 2017, from: http:// themaintainers.org/.

Klein, N. (2013, October 29). How Science is Telling Us All to Revolt. Retrieved November 5, 2017, from: http:// www.newstatesman.com/2013/10/sci ence-says-revolt.

Klein, N. (2015). This Changes Everything: Capitalism vs. the Climate. New York: Simon and Schuster.

Krech III, Sh. (2000). The Ecological Indian: Myth and History. New York, London: W. W. Norton \& Company.

Littler, J. (2008). Radical Consumption: Shopping for Change in Contemporary Culture. Berkshire: Open University Press.

Motesharrei, S., Rivas, J., \& Kalnay, E. (2014). Human and Nature Dynamics (HANDY): Modeling Inequality and use of Resources in the Collapse or Sustainability of Societies. Ecological Economics.

Opris, I. (2013, November 19). Interlaminar Microcircuits Across Neocortex: Repair and Augmentation. Frontiers in Systems Neuroscience. doi: 10.3389/fnsys.2013.00080.

Polimeni, J. M., Mayumi K., Gianpietro, M., \& Alcott, B. (2008). The Jevons Paradox and the Myth of Resource Efficiency Improvements. London, Sterling, VA: Earthcan.

Sartre, J.-P. (1960). Critique de la raison dialectique (précédé de Questions de 
méthode), Tome I, Théorie des ensembles pratiques. Paris: Gallimard.

Spelman, E. V. (2002). Repair: The impulse to restore in a fragile world. Boston: Beacon Press.

Toffler, A. (1970). Future Shock. Random House.
World Hunger Again on the Rise, Driven by Conflict and Climate Change, New UN Report Says. (2017, September). Retrieved November 5, 2017, from: http://www.fao.org/news/story/en/ite m/1037253/icode/. 